\title{
Work Planner
}

Use this chart to plan your study schedule.

\begin{tabular}{|c|c|c|}
\hline Learning Activity & Guide Time & Resource \\
\hline $\begin{array}{l}\text { Work through Workbook } \\
\text { Sections } 1-3\end{array}$ & 30 mins & $\mathbf{w}$ \\
\hline $\begin{array}{l}\text { Do Self Check Exercise 1: } \\
\text { 'Functions of meetings' }\end{array}$ & 20 mins & \\
\hline $\begin{array}{l}\text { Work through Workbook } \\
\text { Section } 4\end{array}$ & 30 mins & \\
\hline $\begin{array}{l}\text { Work through Workbook } \\
\text { Section } 5\end{array}$ & 45 mins & \\
\hline $\begin{array}{l}\text { Do Self Check Exercises 2: } \\
\text { 'Terminology of Meetings'; and } \\
\text { 3: 'Meeting Procedures' }\end{array}$ & 30 mins & \\
\hline $\begin{array}{l}\text { Work through Workbook } \\
\text { Sections } 6 \text { and } 7\end{array}$ & 45 mins & \\
\hline $\begin{array}{l}\text { Do Self Check Exercise 4: } \\
\text { 'Practice in taking minutes' }\end{array}$ & 60 mins & \\
\hline $\begin{array}{l}\text { Read the beginning of Section } \\
8 \text { (stop before Section } 8.1 \text { ) }\end{array}$ & 5 mins & \\
\hline $\begin{array}{l}\text { Do Self Check Exercise 5: } \\
\text { 'Chairmanship in action' }\end{array}$ & 20 mins & \\
\hline $\begin{array}{l}\text { Work through the rest of } \\
\text { Workbook Sections } 8 \text { and } 9\end{array}$ & 40 mins & \\
\hline $\begin{array}{l}\text { Do Self Check Exercise 6: } \\
\text { 'Preparations for a meeting' }\end{array}$ & 60 mins & \\
\hline $\begin{array}{l}\text { Undertake the Tutor Review } \\
\text { Exercise }\end{array}$ & $120-150$ mins & S \\
\hline Total Guide Time & 8-9 hrs & \\
\hline
\end{tabular}

